\title{
Universal estimation of cardiovascular risk in multi-risk constellations - a "relativity theory" for global risk calculation
}

\author{
Jörg Piper
}

\section{Author:}

Piper, Jorg, Prof. Dr.

Senior Consultant

Department for Internal

Medicine

and Cardiovascular

Medicine

Clinic Meduna

Clara-Viebig road 4

D-56864 Bad Bertrich

Germany

Email: webmaster@dr-

piper.de,

webmaster@prof-piper.de

Phone: +49-(0)2674-182-

3184

Fax: +49-(0)2674-182-

3182

\section{Conflicts of interest:}

None declared.

DOI:http://dx.doi.org/10.18

103/mra.v3i3.475

\begin{abstract}
According to various published studies, at least 26 cardiovascular risk factors can contribute to the individual cardiovascular risk. For all of these risk factors quantitative risk multipliers are known which can be systematically derived from various epidemiological findings.
\end{abstract}

On the other hand, only a few risk factors are considered by the risk scores established (FRAMINGHAM, PROCAM, ESC and HEART score, for instance). Thus, a relevant proportion of patients affected with myocardial infarction or other cardiovascular events do not belong to a high risk group according to these scores.

Thus, alternative tools for universal risk calculation are desirable to improve the significance and sensitivity of such estimations.

Based on "traditional" risk factors considered by the scores mentioned, mathematical analyses were carried out to describe coincidences of various risk factors with regard to the resulting total risk. Their quantitative synergism and relativity can be mathematically described by a specific hyperbolic tangent function derived from the PROCAM score.

By other formulas PROCAM risk calculated in this way can be transformed into corresponding FRAMINGHAM and ESC risk which are targeted at other critical end points.

We consider that the special interaction of risk factors described in our mathematical models can be regarded as a general law of nature so that our formulas could be used for universal risk estimations in all risk constellations imaginable, even when multiple risk factors are coincident.

\section{Key words:}

Risk factors, interaction, estimation, calculation, score, Framingham, PROCAM, ESC, mathematical models, multirisk constellations, cardiovascular event, myocardial infarction, cardiovascular death 


\section{Introduction}

Several risk scores are established for calculating cardiovascular risk.

FRAMINGHAM [23] PROCAM [3, 5, 20] and ESC score [10] are most commonly used. Some more risk scores have been derived from these scores. Thus, for instance, the HEART score [12] is a derivate from the ESC score, and the AGLA score [33] is derived from the PROCAM score.

All of these risk scores are only based on a few risk factors. Several other risk factors detected as additional relevant determinants for cardiovascular risk are not considered by these scores. Moreover, some risk factors are qualitatively considered ("yes" or "no", "existing" or "not existing"), although they modulate the cardiovascular risk quantitatively. Thus, for instance, risk associated with smoking is determined by the number of cigarettes smoked and the cardiovascular risk associated with diabetes mellitus is strongly influenced by the individual HbA1c level. Nevertheless, smoking and diabetes mellitus (so far considered) are managed as qualitative determinants by the risk scores established.

Moreover, these scores are different with regard to the risk factors considered.

FRAMINGHAM score: age, gender, smoking ("yes"/"no"), diabetes mellitus ("yes"/"no"), familiar clustering, systolic blood pressure, lipid levels (HDL, LDL, triglycerides)

PROCAM score ("health check"): age, gender, smoking ("yes"/"no"), diabetes mellitus ("yes"/"no"), systolic and diastolic blood pressure, lipid levels (LDL, HDL, triglycerides)

ESC score: age, gender, smoking ("yes"/"no"), total cholesterol, systolic blood pressure.
On the other hand, we could learn from the INTERHEART study [40] that cardiovascular risk is determined by much more risk factors than taken into account by these scores. At least 26 risk factors can contribute to cardiovascular risk. This background corresponds to the fact that circa 40 - 50 percent of patients with myocardial infarction belong to low or moderate risk groups according to usual risk scores mentioned.

Another problem arises from multi-risk constellations. In clinical practice global risk estimations are often made by use of a simple "country saying": numerical risk associated with defined single risk factors can be multiplied to a resulting global risk when different risk factors are coincident. Example: When Risk factor "a" leads to reduplication and risk factor " $b$ " to triplication of cardiovascular risk, the global risk resulting from a coincidence of both factors "a" and "b" will be sextupled $(2 \times 3=6)$. By use of the risk scores mentioned, however, cardiovascular risk is calculated in percent. Thus, multiplying of percent values will lead to irrational results, especially when the limit of 100 percent is exceeded.

In multi-risk constellations the dominance of a singular risk factor will be successively lowered the more other, concurrent risk factors are present. This phenomenon ("relativity of a risk factor") was recently evaluated with regard to hypertension [7].

Lastly, different risk scores are focused on different "end points". The FRAMINGHAM score is targeted on all events associated with coronary heart disease (angina pectoris, myocardial infarction and myocardial death). The PROCAM score is a morbidity score focused at myocardial infarction. The ESC score, however, is a mortality score, calculating the risk for cardiovascular death.

In view of these problems and limitations this paper presents a new universal 
algorithm describing coincidences and relativities of risk factors and risk scores. It can be used for risk estimation in each sort of cardiovascular risk constellation. In difference from conventional risk scores quantitative factors such as smoking or diabetes mellitus are considered quantitatively as far as possible. Thus, the mathematical models presented can particularly be used for estimation of

\section{Materials and methods}

By intensive investigation of several published original studies and secondary sources commenting their results, quantitative aspects of all risk factors and corresponding cardiovascular risk were systematically compiled. Various "model patients" affected with several coincident risk factors were "virtually" created representing low, moderate and high risk constellations. For each risk constellation, the resulting risk was first calculated by use of the PROCAM, FRAMINGHAM and ESC score. In this way, comparative risk estimations could be carried out with regard to different scores. In a second step, well known single risk levels obtained from various studies and secondary sources cardiovascular risk resulting from multirisk constellations including all risk factors known nowadays. Moreover, risk levels can be converted from one risk score to the other so that mortality and morbidity can be simultaneously estimated The models described may be regarded as a first step to a universally applicable "relativity-theory" of risk factors and risk scores, especially in multi-risk constellations. were multiplied by each other and compared with the score-based results. By this means effects of single risk factors and their coincidence could be mathematically investigated. Moreover, quantitative risk levels calculated with different scores were used for developing conversion formula so that PROCAM risk can be converted into FRAMINGHAM risk and ESC risk.

The following traditionally accepted risk constellations and ranges were used in "model patients" for elaborating the mathematical tools and their adjustment to the PROCAM, FRAMINGHAM and ESC score: age, blood pressure, lipid levels, smoking, diabetes mellitus and familial clustering; further details are compiled in the text box.

\section{Risk factors and risk ranges used for mathematical calculations:}

- Age: 40 - 60 years

- Blood pressure: 130 - $180 \mathrm{mmHg}$ systolic, 80 - $95 \mathrm{mmHg}$ diastolic

- Total cholesterol: 6,4 - 9,0 mmol/1

- LDL-cholesterol: 3,8 - 5,2 mmol/1

- HDL-cholesterol: 0,7 - 1,4 mmol/1

- Triglycerides: 1,7 - 2,9 mmol/1

- Optional additional risks: smoking, diabetes mellitus, familial clustering.

Based on these risk factors and risk ranges, several "model cases" were created with various combinations of the risk factors mentioned above. For all of these cases comparative risk calculations were carried out, using the PROCAM, FRAMINGHAM and ESC score. In separate steps, the basal risk associated with age (see section "Results", Table $1[3,20])$ was multiplied with risk multipliers investigated (see section "Results", Table 2). Thus all risk levels calculated by use of the scores could 
be compared with corresponding risk levels resulting from multiplying single risk values according to the Tables 1 and 2.

Based on these comparative calculations, mathematical models were elaborated to estimate the resulting total risk also in cases with a lot of coincident risk factors. Moreover, algorithms were developed to convert each sort of risk constellation from one score to the other (PROCAM to FRAMINGHAM, PROCAM to ESC).

The following risk factors were not separately considered, because they "overlap" with other risk factors: - Apolipoprotein A1 and B because of their correlation to the HDL- and LDLcholesterol

- Left ventricular hypertrophy because of its correlation to hypertension - Type A- person because of the correlation to psychosocial stress.

According to the PROCAM score patients were divided into three categories of individual risk: Low risk $(<10 \%)$, moderate risk $(10 \%-20 \%)$, high risk (> $20 \%)$.

\section{Results}

\subsection{Investigation of risk factors and risk multipliers}

By use of the PROCAM score the "physiological" cardiovascular risk depending on age was estimated as follows (Table 1):

Table 1:

Cardiovascular risk associated with age derived from the PROCAM score $[3,5,20]$

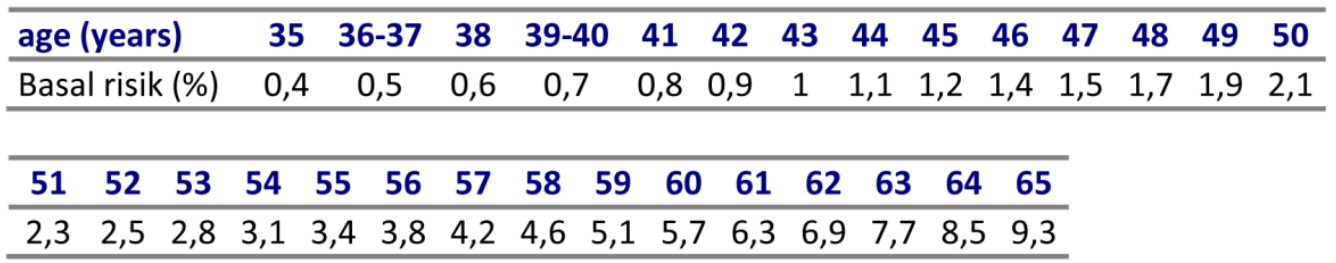

These levels of basal risk associated with age were calculated for healthy male persons who are not affected with relevant risk factors (LDL-cholesterol $3.1 \mathrm{mmol} / \mathrm{l}$, HDL-Cholesterol $1.4 \mathrm{mmol} / \mathrm{l}$, triglycerides $1.7 \mathrm{mmol} / \mathrm{l}$, systolic blood pressure 130 $\mathrm{mmHg}$ ). For women, corresponding risk levels are lower (circa a quarter) according to suggestions of the PROCAM study group. This basal risk determined by age is relevant for each individual regardless of whether affected with other risk factors or not. As defined by the PROCAM algorithm, the risk values compiled in Table 1 (in percent) are related to the manifestation of a fatal or non fatal myocardial infarction calculated for a period of the following 10 years. With regard to the age, corresponding risk levels remain "low" up to the "cut-off" of 65 years.

Based on literature quantitative risk multipliers were complied for "traditional" risk factors generally accepted and evaluated already decades ago (Table 2) and for several "new" risk factors being in the current focus of interest (Table 3). According to the findings of the INTERHEART study three protective "bonus factors" are relevant for reducing cardiovascular risk (Table 4). Moreover, some fixed numeric multipliers for defined risks were published by several authors 
(Table 5). These multipliers can be used for risk estimations in general, leading to average risk levels without regarding individual quantities. Lastly, the grade of average coronary calcification can be evaluated by high resolution computer tomography and quantified by the AGATSON score (Table 6, [1, 2, 25]).

Table 2: Risk multipliers for „traditional” risk factors

\begin{tabular}{lcccc}
\hline total cholesterol $(\mathrm{mmol} / \mathrm{l})$ & $<\mathbf{5 , 2}$ & $\mathbf{5 , 2 - 6 , 2}$ & $\mathbf{6 , 2 - 7 , 3}$ & $>\mathbf{7 , 3}$ \\
\hline risk multiplier $[3,4,19]$ & 1 & 1,5 & 1,9 & 3 \\
\hline
\end{tabular}

\begin{tabular}{|c|c|c|c|c|c|c|c|c|c|c|c|}
\hline LDL-cholesterol (mmol/l) & 3,1 & 3,6 & 4,1 & $4,7 \quad 5$ & $5,2 \quad 5$, & $5,7 \quad 6,2$ & & & & & \\
\hline risk multiplier $[3,4,19]$ & 1 & 1,3 & 1,8 & 2,3 & $3, \varepsilon$ & 3,8 & & & & & \\
\hline HDL-cholesterol (mmol/l) & 1,4 & 1,3 & 1,2 & $1,0 \quad 0,5$ & $9 \quad 0,8$ & 80,6 & & & & & \\
\hline risk multiplier $[3,4,19]$ & 1 & 1,3 & 1,4 & $1,6 \quad 1,5$ & ,9 2,1 & 12,4 & & & & & \\
\hline cholesterol-HDL-ratio & 3,5 & 4 & 4,5 & 5 & 5,5 & 6 & 6,5 & 7 & 7,5 & 8 & 8,5 \\
\hline risk multiplier $[3,4,19]$ & 1 & 1,3 & 1,45 & 1,65 & 2,3 & 2,65 & 3,3 & 4 & 5,3 & 6 & 9,3 \\
\hline
\end{tabular}

\begin{tabular}{lcccc}
\hline triglycerides (mmol/l) & $\mathbf{1 , 1}$ & $\mathbf{2 , 3}$ & $\mathbf{3 , 4}$ & $\mathbf{4 , 5}$ \\
\hline risk multiplier $[3,4,19]$ & 1 & 1,2 & 1,4 & 1,6 \\
\hline
\end{tabular}

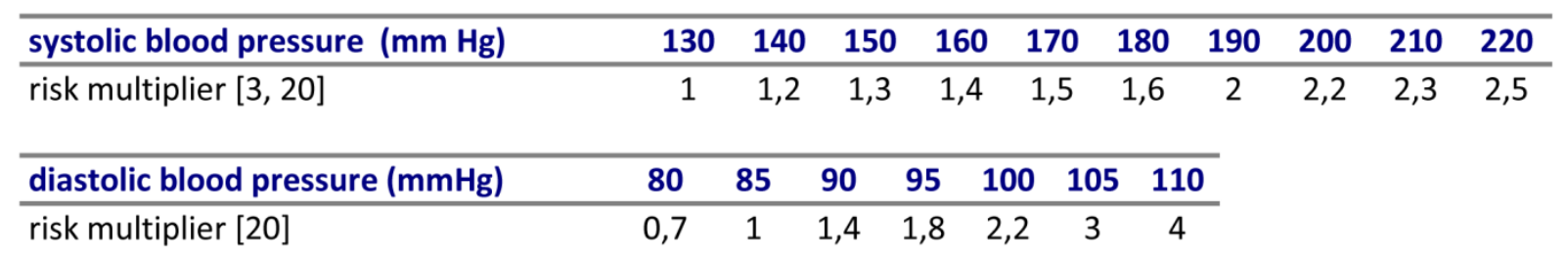

\begin{tabular}{lccccc}
\hline smoking (number of cigaretts per day) & $<\mathbf{1 0}$ & $\mathbf{2 0}$ & $\mathbf{3 0}$ & $\mathbf{4 0}$ & $>\mathbf{5 0}$ \\
\hline risk multiplier for myocardial infarction [36] & 1,5 & 2 & 2,5 & 3 & 4 \\
\hline risk multiplier for cancer [36] & 4 & 7 & 20 & 30 & 40 \\
\hline
\end{tabular}

\begin{tabular}{lccccc}
\hline HbA1c & $\mathbf{6 , 0 - 6 , 5}$ & $\mathbf{6 , 5 - 7 , 0}$ & $\mathbf{7 , 0 - 9 , 0}$ & $\mathbf{9 , 0 - 1 1 , 0}$ & $\mathbf{1 1 , 0 - 1 3 , 0}$ \\
\hline risk multiplier for macroangiopathy [CHD) [35] & 1 & 1,25 & 1,9 & 2,5 & 3,1 \\
\hline risk multiplier for mikroangiopathy [35] & 1 & 2 & 6 & 13 & 25 \\
\hline
\end{tabular}

\begin{tabular}{lccccc}
\hline Body-Mass-Index (BMI) & $<\mathbf{2 5}$ & $\mathbf{2 5 - 2 8}$ & $\mathbf{2 8}$ & $\mathbf{3 0}$ & $>\mathbf{3 2}$ \\
\hline risk multiplier $[15,16,27,32$, & 1 & 1,5 & 2 & 3 & 4
\end{tabular}

41]

\begin{tabular}{lcc}
\hline familial clustering / aggregation & no & yes \\
\hline risk multiplier [20] & 1 & 1,5 \\
\hline
\end{tabular}


Table 3: Risk multipliers for „new“ risk factors

\begin{tabular}{lcccccc}
\hline Waist-to-hip-ratio / WHR - men & $<\mathbf{0 . 8 5 9}$ & $\mathbf{0 , 8 6 0 - 0 , 9 0 9}$ & $\mathbf{0 , 9 1 0 - 0 , 9 4 9}$ & $\mathbf{0 , 9 5 0 - 0 , 9 9 9}$ & $\mathbf{1 , 0 0 0 - 1 , 0 3 9}$ & $>\mathbf{1 , 0 4}$ \\
\hline risk multiplier [27, 39] & 1 & 1,6 & 2,3 & 2,9 & 3,6 & 5 \\
\hline & & & & & & \\
\hline Waist-to-hip-ratio/ WHR - women & $<\mathbf{0 , 7 2 0}$ & $\mathbf{0 , 7 2 0 - 0 , 7 5 9}$ & $\mathbf{0 , 7 6 0 - 0 , 7 9 9}$ & $\mathbf{0 , 8 0 0 - 0 , 8 3 9}$ & $\mathbf{0 , 8 4 0 - 0 , 8 7 9}$ & $>\mathbf{0 , 8 8}$ \\
\hline risk multiplier [27, 39] & 1 & 1,6 & 2,3 & 2,9 & 3,6 & 5 \\
\hline
\end{tabular}

\begin{tabular}{lcc}
\hline waist circumference - men $(\mathrm{cm})$ & $>94$ & $>102$ \\
\hline waist circumference - women $(\mathrm{cm})$ & $>80$ & $>88$ \\
\hline risk multiplier $[27,39]$ & $1,5-2,5$ & $3-8$ \\
\hline
\end{tabular}

\begin{tabular}{lcc}
\hline lipoproteine (a) (mg/l) & $<\mathbf{2 0 0}$ & $>\mathbf{2 0 0}$ \\
\hline risk multiplier $[11,22]$ & 1 & 2 \\
\hline
\end{tabular}

\begin{tabular}{|c|c|c|c|c|c|c|}
\hline \multicolumn{3}{|c|}{ high sensitivity C-reactive proteine (hs-CRP) (mg/I) } & $<0,7$ & $0,7-1,1$ & $1,2-1,9$ & 2,0 \\
\hline risk multiplier $[9,13,28,29$, & 38] & & 1 & 1,2 & 1,4 & 1, \\
\hline homocysteine (micromol/I) & $<10$ & 12 bis 1315 & 17 bis 18 & $>20$ & & \\
\hline risk multiplier $[8,13,24]$ & 1 & 1,5 & 3 & 4 & & \\
\hline fibrinogen (factor I) & normal & blood level & creased blo & od level & & \\
\hline risk multiplier [31] & & 1 & 1,5 & & & \\
\hline chronic chlamydia pneumon & niae infe & ction & no & yes & & \\
\hline risk multiplier [30] & & & 1 & 2,6 & & \\
\hline psychosocial stress & low & much & & & & \\
\hline risk multiplier [40] & 1 & 2,7 & & & & \\
\hline microalbuminuria (mg/dl) & & 10 bis 14 & 15 bis 29 & 30 bis 300 & $>\mathbf{3 0 0}$ & \\
\hline $\begin{array}{l}\text { risk multiplier }[6,14,17,18 \text {, } \\
21,26,34,37]\end{array}$ & & 1,5 & 2 & 3 & 8 & \\
\hline
\end{tabular}

Table 4: Multipliers of ,bonus factors“ [40]

\begin{tabular}{lccc}
\hline bonus factors & fruits / vegetables & sportive activity & moderate alcohol \\
\hline risk multiplier & 0,7 & 0,85 & 0,9 \\
\hline
\end{tabular}


Table 5: Fixed risk multipliers, published for general risk estimations

\begin{tabular}{|c|c|c|c|c|c|}
\hline & $\begin{array}{c}\text { Procam } \\
{[3,4]}\end{array}$ & $\begin{array}{c}\text { Framingham } \\
{[23]}\end{array}$ & $\begin{array}{c}\text { Interheart } \\
{[40]}\end{array}$ & $\begin{array}{c}\text { Rifai \& Ridke } \\
\text { [29] }\end{array}$ & $\begin{array}{c}\text { Clearfield } \\
{[9]}\end{array}$ \\
\hline smoking & 1,7 & 3 & 2,87 & & \\
\hline diabetes mellitus & 1,5 & 1,5 & 2,37 & & \\
\hline familial clustering & 1,5 & & & & \\
\hline hypertension & & & 1,91 & & \\
\hline dyslipidemia & & & 3,25 & & \\
\hline $\begin{array}{l}\text { abdominal fat } \\
\text { deposition }\end{array}$ & & & 1,19 & & \\
\hline stress & & & 2,67 & & \\
\hline sportive activity & & & 0,86 & & \\
\hline alcohol (moderate) & & & 0,91 & & \\
\hline fruits and vegetables & & & 0,7 & & \\
\hline lipoproteine (a) & & & & 1,4 & \\
\hline homocystein & & & & 1,8 & \\
\hline hs-CRP & & & & & 2 \\
\hline occasional smoker & & & 1,4 & & \\
\hline chain-smoker & & & 9 & & \\
\hline $\begin{array}{l}\text { smoking and metabolic } \\
\text { syndrome }\end{array}$ & & & 69 & & \\
\hline
\end{tabular}

Table 6: Risk multipliers associated with coronary calcification (AGATSTON index)

\begin{tabular}{lccc}
\hline coronary calcification (Agatston score) & $<100$ & $100-400$ & $>400$ \\
\hline risk multiplier $[1,2,25]$ & 1 & 2 & 3,5 \\
\hline
\end{tabular}

3.2. Mathematical model for global risk calculation (according to PROCAM score)

When the "traditional" risk values presented in the Tables $\mathbf{1}$ and $\mathbf{2}$ are multiplied by each other in various "virtual" risk constellations as described above (Table 7), the results of multiplications are approximately identical with the corresponding risk levels calculated with the PROCAM score, as long as the product is lower than $30 \%$. In other cases, when multiplications of single risk levels exceed $30 \%$, the product " $x$ " can be processed by the following hyperbolic tangent function (Fig. 1) to estimate a realistic total risk " $\mathrm{f}(\mathrm{x})$ " according to the PROCAM score: $\mathrm{f}(\mathrm{x})=100 \tanh (0,008 \mathrm{x})[\%]$. 


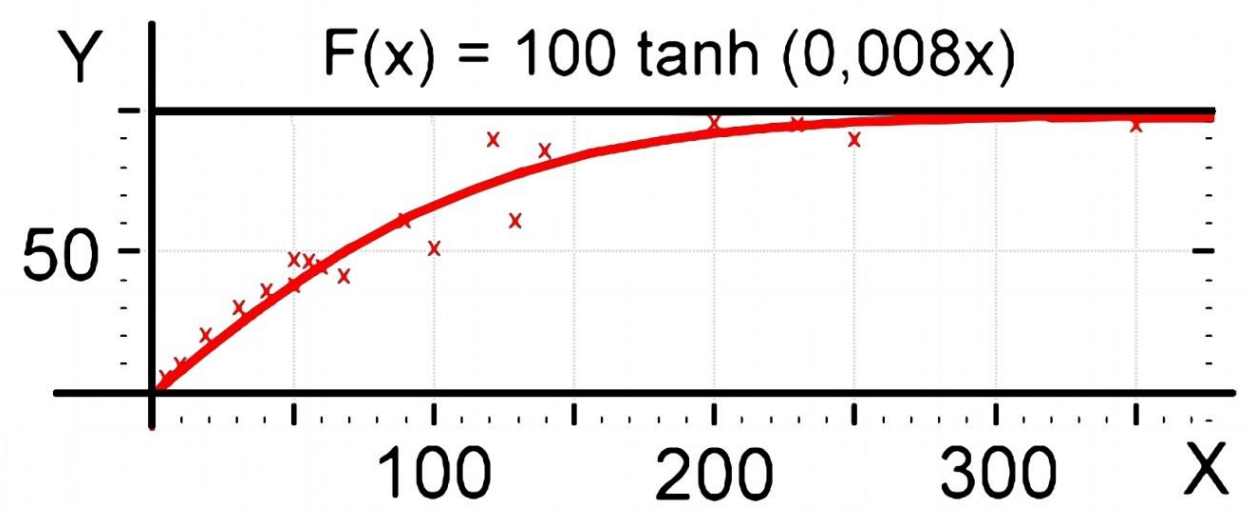

Fig. 1: Regression graph for calculation of total risk in constellations characterized by multiple coincident risk factors $X$-Axis: products of single risk multiplications

$Y$-Axis: resulting total risk, adjusted to the PROCAM score

The formula describes synergism and relativity of multiple coincident risk factors based on the PROCAM score; it is derived from the regression graph shown in Fig. 1. It defines the risk for myocardial infarction based on a period of 10 years, calculated for male individuals aged from 30-65 years. The corresponding risk levels for women are circa 0.25 -fold lower according to the suggestions of the PROCAM Study group. The higher is the number of risk factors or the product of risk factor multiplications, the lower is the contribution of each single risk factor to the resulting total risk.

\subsection{Mathematical transformation of PROCAM risk into FRAMINGHAM risk}

PROCAM risk levels can be transformed to FRAMINGHAM-risk levels to estimate higher risk levels for all manifestations of coronary heart disease. Conversing factors mathematically derived are presented in

\section{Table 8.}

Based on the PROCAM risk value "P", the corresponding FRAMINGHAM risk level "FR" can be approximately calculated by a conversion factor " $F$ ", the PROCAM risk value "P" has to be multiplied with:

The exponent " $\mathrm{n}$ " ranges from 0.5 to 0.8 . The FRAMINGHAM risk range corresponding with a well defined PROCAM risk can be described and estimated based on the graphs shown in Fig. 2 (x-axis: PROCAM risk, y-axis: conversing factor):

$$
F=P \times\left(6 \times \frac{1}{P^{n}}+1\right), \quad F R=F \times P
$$


Medical Research Archives

Universal estimation of cardiovascular risk

Table 7: Comparative estimations of total risk for myocardial infarction, based on the PROCAM-score and single risk factor multipliers, according to the data compiled (table of values for Fig. 1)

\begin{tabular}{|c|c|}
\hline $\begin{array}{l}\text { Products of single risk factor } \\
\text { multiplications }\end{array}$ & $\begin{array}{r}\text { Corresponding } \\
\text { PROCAM risk (\%) }\end{array}$ \\
\hline 5 & 5 \\
\hline 10 & 10 \\
\hline 15 & 15 \\
\hline 20 & 20 \\
\hline 25 & 25 \\
\hline 30 & 30 \\
\hline 40 & 31 \\
\hline 50 & 38 \\
\hline 60 & 44 \\
\hline 70 & 51 \\
\hline 80 & 56 \\
\hline 90 & 61 \\
\hline 100 & 66 \\
\hline 110 & 70 \\
\hline 120 & 74 \\
\hline 130 & 78 \\
\hline 140 & 80 \\
\hline 150 & 83 \\
\hline 160 & 85 \\
\hline 170 & 87 \\
\hline 180 & 89 \\
\hline 190 & 91 \\
\hline 200 & 92 \\
\hline 210 & 93 \\
\hline 220 & 94 \\
\hline 230 & 95 \\
\hline 240 & 96 \\
\hline 250 & 96 \\
\hline 260 & 97 \\
\hline 270 & 97 \\
\hline 280 & 98 \\
\hline 290 & 98 \\
\hline 300 & 98 \\
\hline 310 & 98 \\
\hline 320 & 99 \\
\hline$>320$ & 99 \\
\hline
\end{tabular}


Table 8: Minimum and maximum conversing factors, PROCAM risk can be multiplied with when corresponding FRAMINGHAM risk levels are to be estimated (table of values for Fig. 2)

\begin{tabular}{|c|c|}
\hline $\begin{array}{c}\text { Procam risk } \\
(\%)\end{array}$ & $\begin{array}{c}\text { Conversing factors } \\
\text { (minimum; maximum) }\end{array}$ \\
\hline 1 & $7 ; 7$ \\
\hline 2 & 4,$4 ; 5,2$ \\
\hline 3 & 3,$5 ; 4,5$ \\
\hline 4 & 3,$0 ; 4,0$ \\
\hline 5 & 2,$7 ; 3,7$ \\
\hline 6 & 2,$4 ; 3,4$ \\
\hline 7 & 2,$3 ; 3,3$ \\
\hline 8 & 2,$3 ; 3,1$ \\
\hline 9 & 2,$0 ; 3,0$ \\
\hline 10 & 1,$9 ; 2,9$ \\
\hline 11 & 1,$9 ; 2,8$ \\
\hline 12 & 1,$8 ; 2,7$ \\
\hline 13 & 1,$8 ; 2,7$ \\
\hline 14 & 1,$7 ; 2,6$ \\
\hline 15 & 1,$7 ; 2,5$ \\
\hline 16 & 1,$7 ; 2,5$ \\
\hline 17 & 1,$6 ; 2,5$ \\
\hline 18 & 1,$6 ; 2,4$ \\
\hline 19 & 1,$6 ; 2,4$ \\
\hline $20-23$ & 1,$5 ; 2,3$ \\
\hline $24-25$ & 1,$5 ; 2,2$ \\
\hline $26-27$ & 1,$4 ; 2,2$ \\
\hline $28-32$ & 1,$4 ; 2,1$ \\
\hline $33-34$ & 1,$4 ; 2,0$ \\
\hline $35-39$ & 1,$3 ; 2,0$ \\
\hline $40-49$ & 1,$3 ; 1,9$ \\
\hline 50 & 1,$3 ; 1,8$ \\
\hline$>50$ & 1,$3 ; 1,8$ \\
\hline
\end{tabular}




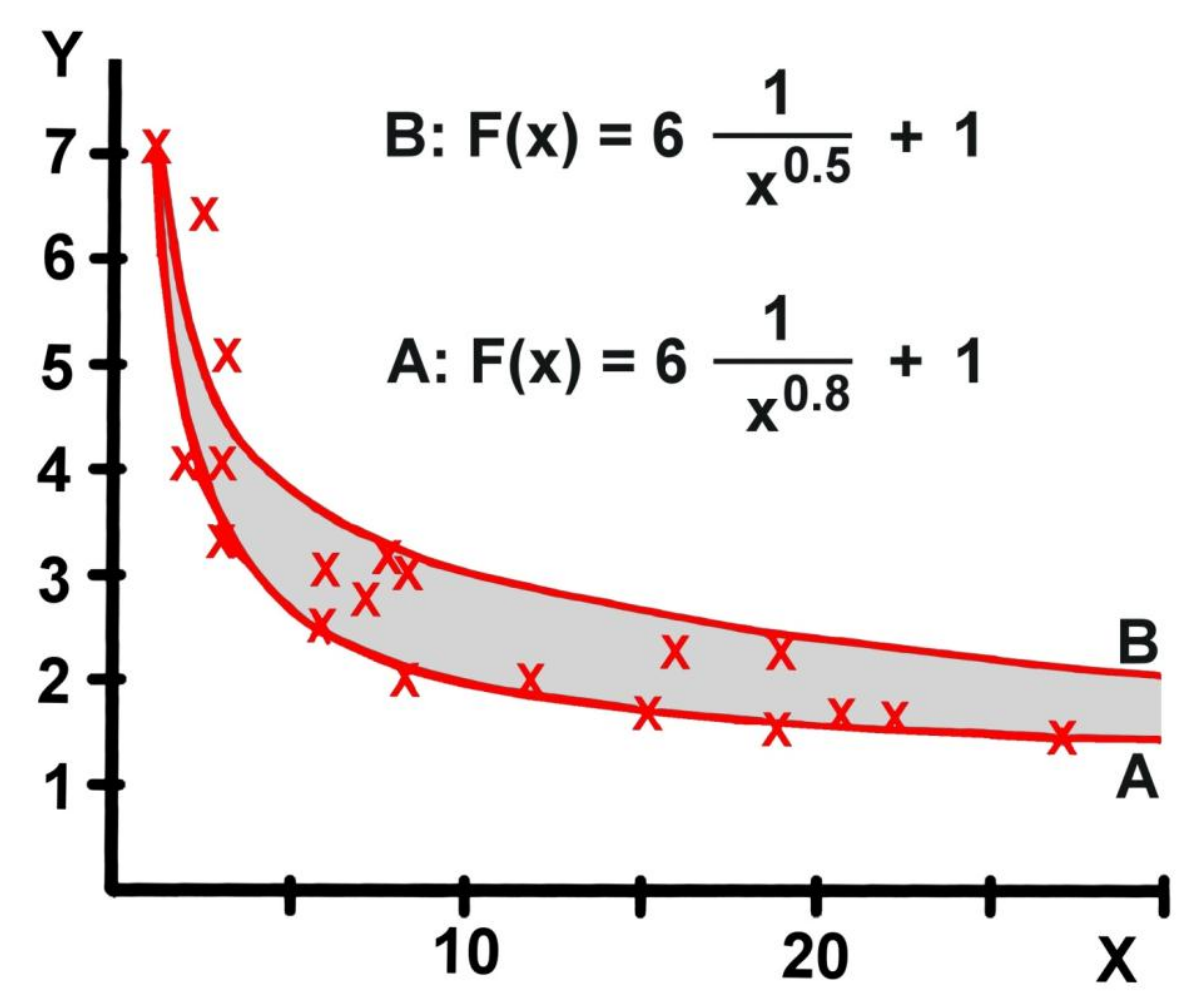

Fig. 2: Conversing factors for transforming PROCAM risk into FRAMINGJAM risk. $X$-Axis: PROCAM-risks in percent $Y$-Axis: conversing factors (multipliers for estimation of corresponding FRAMINGHAM-risk levels

Graph A: minimum conversing factors

Graph B: maximum conversing factors

Graph A (exponent $\mathrm{n}=0.8$ ) and graph $\mathrm{B}$ (exponent $\mathrm{n}=0.5$ ) correspond with the minimal (A) and maximal (B) conversing factors; both graphs are suitable for estimating the approximate range of FRAMINGHAM risk levels corresponding to PROCAM risk.

In low risk constellations according to PROCAM, the average corresponding
FRAMIMGHAM-risk is about 3.5-fold higher, in moderate risk constellations about 2.5-fold, and in high risk constellations about 2.0-fold or lower. When PROCAM risk values are higher than $30 \%$, there remain no relevant differences to the corresponding FRAMINGHAM risk levels; this finding should be noticed in practice. 
3.4. Mathematical transformation of PROCAM risk into ESC risk

Calculated PROCAM risk can be transformed into ESC risk to estimate the corresponding lower risk for cardiovascular death. These calculations can be separately carried out for so-called "low risk" and "high risk" countries. Some conversion factors used for multiplying PROCAM risk levels in order to obtain corresponding ESC risk levels are compiled in Table 9.

Table 9: PROCAM risk and corresponding ESC risk for high risk- and low riskcountries (table of values for Fig. 3)

\begin{tabular}{|c|c|c|}
\hline \multirow{2}{*}{$\begin{array}{c}\text { PROCAM risk (\%) } \\
1 \\
\end{array}$} & \multicolumn{2}{|c|}{$\begin{array}{c}\text { ESC risk (\%) } \\
\text { (high risk / low risk } \\
\text { countries) }\end{array}$} \\
\hline & 1 & 0 \\
\hline 2 & 1 & 0 \\
\hline 3 & $2-3$ & 1 \\
\hline 5 & $2-7$ & $1-3$ \\
\hline 6 & $2-6$ & $1-3$ \\
\hline 7 & $1-7$ & $1-2$ \\
\hline 8 & $6-7$ & $1-3$ \\
\hline 9 & 4,6 & $2-3$ \\
\hline 11 & 4 & $1-2$ \\
\hline 13 & 3 & 1 \\
\hline 15 & $7-12$ & $3-6$ \\
\hline 16 & 4 & 2 \\
\hline 19 & $3-6$ & 2 \\
\hline 22 & $11-12$ & 6 \\
\hline 28 & 14 & 7 \\
\hline 33 & $10-12$ & 5 \\
\hline 37 & $18-19$ & 9 \\
\hline 38 & 14 & 7 \\
\hline 44 & $12-16$ & $3-7$ \\
\hline 45 & $10-12$ & 5 \\
\hline 60 & $33-34$ & 18 \\
\hline 68 & 24-29 & 13 \\
\hline 74 & $33-34$ & 18 \\
\hline 81 & 24-29 & 13 \\
\hline
\end{tabular}



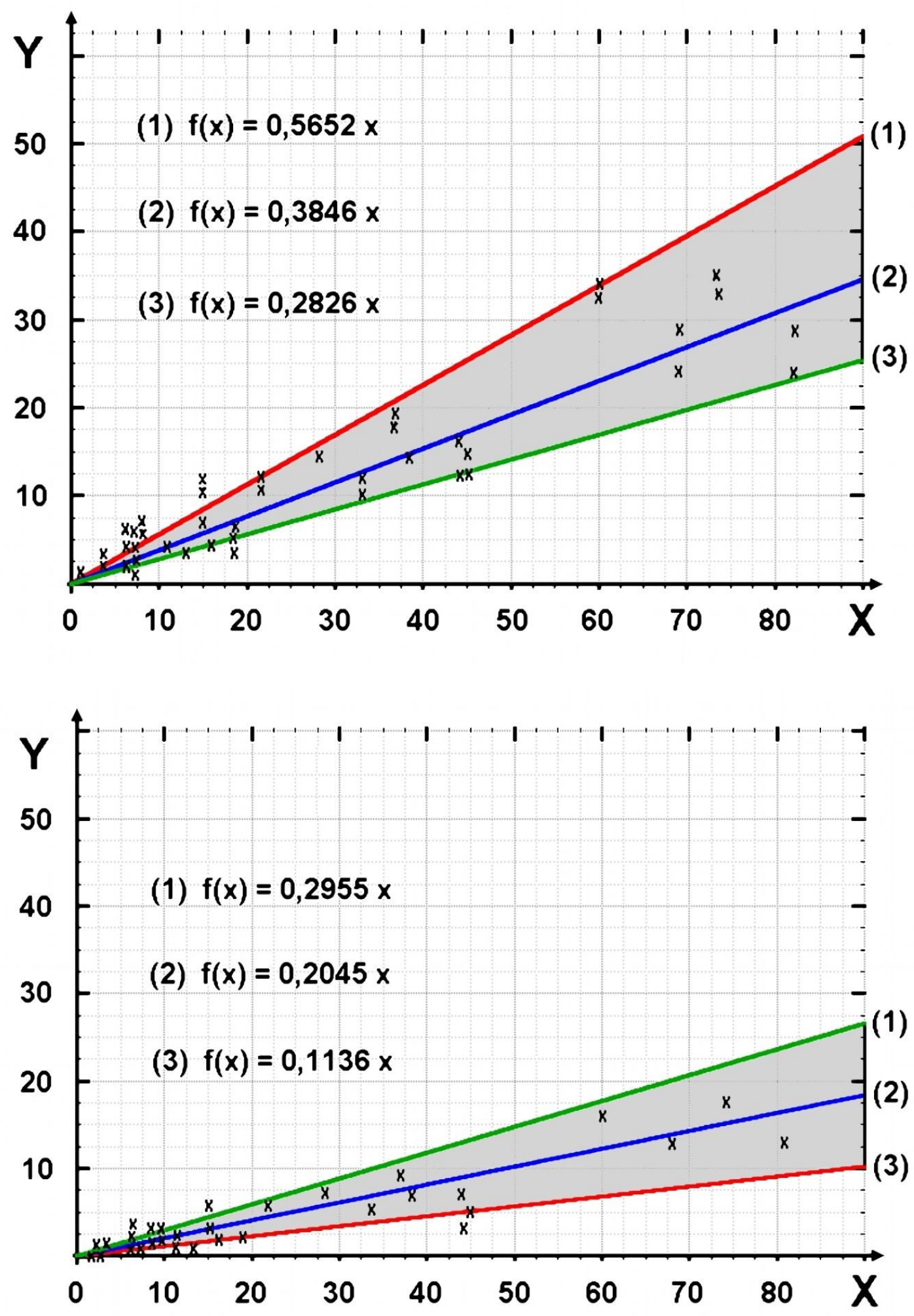

Fig. 3: Regression graphs for converting PROCAM risk into ESC risk, calculations for "high risk countries" (top) and "low risk countrie"s (bottom).

$X$-Axis: PROCAM-risk

$Y$-Axis: Corresponding risk according to the ESC score

Separate graphs for maximum (1), medium/average (2) and minimum (3) risk levels 
As shown in Fig. 3, a calculated PROCAM risk value "P" can be approximately converted to a corresponding ESC score risk level " $\mathrm{E}$ " by linear functions:

$\mathrm{E}=\mathrm{m} \times \mathrm{P}$

The proportionality factor " $\mathrm{m}$ " is different for low and high risk countries.

For high risk countries:

$-\mathrm{m}=0.2826$ (minimum factor)

$-\mathrm{m}=0.3846$ (average factor)

$-\mathrm{m}=0.5652$ (maximum factor).

\section{Implications for practical use}

\subsection{General advices for practical use}

When risk estimations are carried out using the Tables 1-5, some logical aspects should be taken into account in order to avoid overestimation (see text box below).

\subsection{Further hints for practical use}

Firstly risk can be calculated on the basis of age, increased lipid levels and hypertension. These calculations can be carried out by multiplying the risk values compiled in the presented tables or by using the established risk scores including existing computer-based programs.

In cases of smoking and diabetes established scores can be used when calculations based on constant or fixed risk values seem to be adequate. For more differentiated calculations regarding individual blood levels of $\mathrm{HbAlc}$ or the number of smoked cigarettes the tabular data should be preferred.

Additional risks resulting from obesity or increased abdominal fat deposition can be
For low risk countries:

$-\mathrm{m}=0.1136$ (minimum factor)

$-\mathrm{m}=0.2045$ (average factor)

$-\mathrm{m}=0.2955$ (maximum factor).

In high risk countries the risk levels for cardiovascular death are approximately 0.3 - 0.5-fold lower, in low risk-countries nearly $0.1-0.3$-fold lower than the corresponding risk levels for myocardial infarction calculated by the PROCAM algorithm.

estimated by using the values listed in the tables. Moreover, risks resulting from familial disposition can be calculated using the PROCAM-algorithm or the fixed multipliers according to the tables.

In this way, all effects of "traditional" risk factors can be evaluated.

Influences of "newer" risk factors can be calculated based on specific multipliers, too. These factors should be multiplied with each other as described. Thus, further individuals with significant risk can be recognized even when not be identified by the conventional risk scores.

When products of risk factor multiplications exceed $30 \%$, the regression graph and/or the corresponding hyperbolic tangent function can be used to estimate realistic total risk levels adjusted to the PROCAM score (see Fig. 1 and Table 6).

PROCAM risk calculated in the ways described can be transformed into corresponding risk levels based on the FRAMINGHAM and/or ESC score based on conversing factors and linear functions described. These transformations can be 
carried out in all potential risk factor constellations, also in cases with multiple newer risk factors.

Fixed published multipliers can also be used for general risk calculations based on average risk levels and carried out without regarding individual quantities.

All in all, many existing risk constellations can be calculated in the ways described which are not taken into account by the risk scores established.

\section{General aspects which should be noted for risk calculation:}

(1) For calculation of the cholesterol-based risk: total cholesterol or LD-cholesterol and HDL-cholesterol or Cholesterol-HDL-ratio should be used.

(2) For calculation of risk associated with hypertension: risk multipliers for systolic or diastolic blood pressure should be used.

(3) For calculation of risk associated with abdominal fat deposition: WHR or waist circumference should be used.

(4) For calculation of risk associated with obesity: multipliers for BMI, WHR or waist circumference should be used.

(5) For calculation of risk associated with lipoproteine (a): lipoproteine (a) should only be considered when the LDL level exceeds $3.37 \mathrm{mmol} / 1$ as recommended by the

PROCAM study group.

\section{Discussion}

We could learn from several studies, especially the INTERHEART Study, that myocardial infarctions result from a cluster of various risk factors - and from much more risk factors than considered by the established scores. Thus, these scores, even when based on prospective studies, are not suitable for calculating the individual cardiovascular risk in all cases affected with increased risk. Circa $50 \%$ of all patients with myocardial infarction belong to populations with a moderate or low risk according to usual scores. In such cases other risk factors are dominant, which are not taken into account by standard scores.

The mathematical models presented can be used to calculate individual cardiovascular risk in a more universal manner using specific numeric modulators considering all relevant "traditional" and "new" risk factors.
These methods were evaluated based on traditional risk constellations which are considered by the established risk scores based on the results of prospective studies. Nevertheless, the formulas and regression graphs developed can also be used for estimation of risk induced by "new" risk factors investigated by case-control studies.

Of course, mathematical models based on prospective and case-control studies may be regarded as problematic as both types of studies have their characteristic potential bias, especially selection bias (prospective studies) and memory bias (case-control study).

On the other hand, there is no other way at the present to establish mathematical models for global risk estimations with regard to all risk factors currently known, because only a few risk factors have yet been investigated by prospective studies. 
Moreover, it could be considered that the results of the case-controlling INTERHEART-study are not drastically different from the corresponding results of prospective studies, when risk factors are taken into account investigated in both ways by prospective and case control studies.

Using the tables, graphs and formulas presented, physicians can quickly estimate the total cardiovascular risk of their individual patients based on clinical and laboratory diagnostic parameters including "new" risk factors. Moreover, prognostic rankings for all conceivable risk constellations can be made.

Global risk estimations of this sort can be helpful for strategies and individual decisions in cardiovascular prevention aimed at those individuals who might benefit from prevention programs in a significant manner improving their long time-prognosis.

When total risk levels are comparatively estimated based on PROCAM, FRAMINGHAM and ESC score, separate risk estimations for all manifestations of coronary heart disease (FRAMINGHAM), myocardial infarction (PROCAM) and cardiovascular death (ESC score) can be carried out. By these means, the prognostic weights of various risk constellations can be evaluated and compared with special regard to their specific potential complications. Moreover, the scores mentioned can be compared with each other on a mathematical basis.

The relations between the various risk scores mathematically analyzed are congruent with patho-physiological and epidemiological facts. Based on a defined period, e.g. 10 years, in each population the number of individuals with all clinical manifestations of coronary heart disease (CHD) is higher than the number of patients with myocardial infarctions, and the number of patients with myocardial infarctions is higher than the number of fatal cardiovascular events. Moreover, the higher is the total individual risk level, the lower are the numeric differences of all CHD manifestations, myocardial infarctions and cases with cardiovascular death arising in a course of several years. Therefore, different results of risk calculations dependent on different risk scores should not be regarded as inconsistent.

It is desirable that new prospective studies are aimed to "new" risk factors mentioned above, so that the established scores might be expanded including all relevant "new" modulators. In this way, the relevance and predictive "sensitivity" of these scores might be improved, quantitative effects of "new" risk factors derived from casecontrol studies at the present could be corrected in the future, if necessary, and the mathematical models presented here could be checked by multivariate analysis.

Thus, epidemiological research might confirm in the future that the mathematical algorithms developed describe in-fact a law of nature which is valid in all cardiovascular risk factors and their combinations.

A complementary way for risk estimation based on morphological findings is represented by the AGATSTON score [1, 2 , 25]. Coronary calcification indices correspond with cardiovascular risk and can be used as additional risk indicators, especially in high risk constellations (Table 6).

In conclusion, the mathematical applications presented may open the way to global and general risk estimations which could be used for practical advice and treatment as well as for comparative risk calculations in all coincidences or combinations of cardiovascular risk factors. 


\section{References}

[1] Agatston AS, Janowitz WR, Hildner FJ, Zusmer NR, Viamonte M, Detrano R (1990) Quantification of coronary artery calcium using ultrafast computed tomography. J. Am. Coll. Cardiol. 15, 827 $-832$

[2] Arad Y, Spadaro LA, Goodman K (2000) Prediction of coronary events with electron beam cumputed tomography. J. Am. Coll. Cardiol., 36, 1253 - 1260

[3] Assmann, G.: PROCAM health check. Risk factor-based calculator for evaluating individual risk for myocardial infarction, PrevaMed GmbH, interactive DC-ROM for physicians, 2007

[4] Assmann G, Cullen,P, von Eckardstein A, Funke H, Schulte H (1999) The importance of triglycerides as a significant risk factor. Eur. Heart, J., 1, J 7 - J 11

[5] Assmann G, Cullen P, Schulte H (2002) Simple scoring scheme for calculating the risk of acute coronary events based on the 10-year follow-up of the Prospective Cardiovascular Münster (PROCAM) Study. Circulation, 105, 310315

[6] Borch-Johnsen K, Feldt-Rasmussen B, Strandgaard S, Schroll M, Jensen JS (1999) Urinary albumin excretion. An independent predictor of ischemic heart disease. Arterioscler Thromb Vasc Biol 19:1992-1997

[7] Chrubasik-Hausmann, S., Chrubasik, C. (†), Piper, J., Schulte-Mönting, J, Erne, P.

Impact of Risk Factors on Cardiovascular Risk: a Perspective on Risk Estimation in a Swiss Population. Swiss Med Wkly, 2015 (in press)

[8] Clarke R, Lewintron S, Donald A (2001) Underestimation of the importance of homocsteine as a risk factor for cardiovascular disease in epidemiological studies. J. Cardiovasc Risk, 8, 363 - 369

[9] Clerarfield MB (2005) C-reaktives Protein: A new risk assessment tool for cardiovascular disease. JAOA, 105/9: 409 $-416$

[10] Conroy RM, Pyörälä K, Fitzgerald AP et al, on behalf of the SCORE project group (2003) Estimation of ten-year risk of fatal cardiovascular disease in Europe: the SCORE project. Result of a riks estimation study in Europe. Eur Heart J. 24: 987 1003

[11] Craig WY, Neveux LM, Palomaki GE (1998) Lipoprotein(a) as a risk factor for ischemic heart disease: metaanalysis of prospective studies. Clin. Chem., 44: 2301 $-2306$.

[12] European Society of Cardiology (2005) Heartscore: the interactive tool for predicting and managing the risk of heart attack and stroke in Europe. http://www.escardio.org/initiatives/prevent ion/heartscore.htm

http://www.escardio.org/knowledge/decisi on-tools/heartscore-old/Programme-

Download.htm

[13] Fruchart JC, Nierman MC, Stroes ESG, Kastelein JJP, Duriez P (2004) New Risk Factors for Atherosclerosis and Patient Risk Assessment. Circulation, 109(23 suppl. 1), III 15 - III 19

[14] Gerstein HC, Mann JF, Yi Q, Zinman B, Dinneen SF, Hoogwerf B, Halle JP, Young J, Rashkow A, Joyce C, Nawaz S, Yusuf S (2001) Albuminuria and risk of cardiovascular events, death, and heart failure in diabetic and nondiabetic individuals. Jama 286:421-426

[15] Grundy SM (2001) Coronary calcium as a risk factor: role in global risk 
assessment. J. Am. Coll. Cardiol., 27, 1512 $-1515$

[16] Harvard school of puplic health (2005) Health weight. www.hsph.harvard.edu

[17] Hillege HL, Fidler V, Diercks GF, van Gilst WH, de Zeeuw D, van Veldhuisen DJ, Gans RO, Janssen WM, Grobbee DE, de Jong PE (2002) Urinary albumin excretion predicts cardiovascular and noncardiovascular mortality in general population. Circulation 106:1777-1782

[18] Hillege HL, Janssen WM, Bak AA, Diercks GF, Grobbee DE, Crijns HJ, Van Gilst WH, De Zeeuw D, De Jong PE (2001) Microalbuminuria is common, also in a nondiabetic, nonhypertensive population, and an independent indicator of cardiovascular risk factors and cardiovascular morbidity. J Intern Med 249:519-526

[19] Hopkins PN, Wu LL, Hunt SC, Brinton EA (2005) Plasma triglycerides and type III hyperlipidemia are independently associated with premature familial coronary artery disease. J. Am. Coll. Cardiol., 45(7), 1003 - 1012

[20] International Task Force for Prevention of Coronary Heart Disease (2005) Procam Risik Calculator. www.chd-taskforce.com/index.html

[21] Klausen K, Borch-Johnsen K, FeldtRasmussen B, Jensen G, Clausen P, Scharling H, Appleyard M, Jensen JS (2004) Very low levels of microalbuminuria are associated with increased risk of coronary heart disease and death independently of renal function, hypertension, and diabetes. Circulation 110:32-35

[22] Luc G, Bard JM, Arveiler D (2002) Lipoprotein (a) as a predictor of coronary heart desease: the PRIME Study. Atherosclerosis, 163, $377-384$

[23] National Heart Lung, and Blood Institute, National Institute of Health (2002) Framingham Heart Study. www.nhlbi.nih.gov/about/framingham/inde x.html

[24] Nurk E, Tell GS, Vollset SE (2002) Plasma total homocysteine and hospitalizations for cardiovascular disease: the Hordalend Homocysteine Study. Arch. Intern. Med., 162, 1374 - 1381

[25] Raggi P, Callister TQ, Cooil B, He ZX, Lippolis N J, Russo D, Zelinger A, Mahmarian J (2000) Identification of patients at increased risk of first unheralded acute myocardial infarction by electron-beam computed tomography. Circulation 101, 850 - 855

[26] Remuzzi G, Weening JJ (2005) Albuminuria as early test for vascular disease. Lancet 365:556-557

[27] Rexrode KM (2001) Abdominal and total adiposity and risk of coronary heart disease in Men. Int. J. Obes. 25, 1047 1056

[28] Ridker PM, Hennekens CH, Buring JE (2000) C-reactive protein and other markeers of inflammation in the prediction of cardiovascular disease in women. $\mathrm{N}$. Engl. J. Med., 342, 836 - 843

[29] Rifai N, Ridker PM (2001) Proposed cardovascular risk assessment algorithen using high-sensitivity C-reaktive Protein and Lipid Scorering. Clinical Chemistry 47: $28-30$

[30] Saikku P, Leinonen M, Tenkanen L, Ekman MR, Linnanmärki E, Manninen V, Mänttäri M, Frick MM, Huttunen JK (1992) Chronic Chlamydia pneumonoae infection as a risk factor for coronary heart 
disease in the Helsinki Heart Study Ann Int Med 116; 273-278

[31] Scarabin PY, Arveiler D, Amouyel P (2003) Plasma fibrinogen explains much of the difference in risk of coronary heart disease between France an Northern Ireland: the PRIME study. Atherosclerosis, 1666, 103 - 109

[32] Schulte H, Cullen P, Assmann G (1999) Obesity, mortality and cardiovascular disease in the Münster Heart Study (PROCAM). Atherosclerosis, 144, $199-209$

[33] Stuveling E.M. HHL, Bakker S.J.L., Gansevoort R.T.,Gans R.O.B.,de Zeeuw D.,de Jong P. (2003) Urinary albumin excretion and $\mathrm{C}$-reactive protein independently add to the mortality risk. J.Am.Soc.Nephrol. 14:679a

[34] Swiss Atherosclerosis Association, Arbeitsgruppe Lipide und Atherosklerose (AGLA):

AGLA-Risikorechner.

www.agla.ch/risikoberechnung/aglarisikorechner

[35] UK Prospective Diabetes Study (UKPDS) Group (1998) Intensive bloodglucose control with sulphonylureas or insulin compared with conventional treatment and risk of complications in patients with type 2 diabetes (UKPDS 33). Lancet; 332, 837 - 853

[36] U.S. Department of health and human services, puplic health service, national institute of health, national cancer institute (2001) Risk associated with smoking. Monography

13 http://www.krebsgesellschaft.de/downl owd/RisksAssociatedwithSmoking.pdf

[37] Wachtell K, Ibsen $\mathrm{H}$, Olsen $\mathrm{MH}$, Borch-Johnsen K, Lindholm LH, Mogensen CE, Dahlof B, Devereux RB, Beevers G, de Faire U, Fyhrquist F, Julius S, Kjeldsen SE, Kristianson K, LederballePedersen O, Nieminen MS, Okin PM, Omvik P, Oparil S, Wedel H, Snapinn SM, Aurup P (2003) Albuminuria and cardiovascular risk in hypertensive patients with left ventricular hypertrophy: the LIFE study. Ann Intern Med 139:901-906

[38] Wang TJ, Larson MG, Levy D (2002) C-reactive protein is associated with subclinical epicardial coronary caldivication in men and women: the Framingham heart Study. Circulation, 106, $1189-1191$

[39] Welborn TA, Dhaliwal SS, Bennett SA (2003) Waist-hip ratio is the dominant riskfactor predicting kardiovascular risk in Austria. M. J. A. 179, $580-585$

[40] Yusuf S (2004) Effect of protencially modificable risk factors associated with myocardial infarction in 52 countries (the INTERHAERT study): chase control study. Lancet 364, 937 - 952

[41] Yusuf, S (2005) Obesity and the risk of myocardial infarction in 27000 parcipitens from 52 countries: access control-study. Lancet, 366, 1640 - 1649 